\title{
Upconversion in molecular hetero-nonanuclear lanthanide clusters in solution
}

\author{
Richard Knighton, ${ }^{a \dagger}$ Lohona K. Soro, ${ }^{a \dagger}$ Alexandre Lecointre, ${ }^{a}$ Guillaume Pilet, ${ }^{\mathrm{b}}$ Alexandra Fateeva, ${ }^{\mathrm{b}}$ Laurie Pontille, ${ }^{\mathrm{b}}$ \\ Laura Francés-Soriano, ${ }^{c}$ Niko Hildebrandt, ${ }^{c}$ Loïc J. Charbonnière*a \\ aEquipe de synthèse pour l'analyse (SynPA), Institut Pluridisciplinaire Hubert Curien (IPHC), UMR 7178,CNRS/ Université de \\ Strasbourg, ECPM, 25 rue Becquerel, 67087 Strasbourg cedex, France. E-mail: I.charbonn@unistra.frAddress here. \\ ${ }^{b}$ Laboratoire des Multimatériaux et Interfaces (LMI) UMR 5615, Université Claude Bernard Lyon 1, Avenue du 11 novembre \\ 1918, 69622 Villeurbanne cedex, France. \\ 'nanoFRET.com, Laboratoire COBRA (Chimie Organique, Bioorganique, Réactivite et Analyse) CNRS/Université de Rouen \\ Normandie, INSA, 76821 Mont-Saint-Aignan cedex, France
}

Up until now restricted to solid state chemistry and nanoparticles, upconversion (UC) phenomena by which low energy photons are piled up to engender higher energy emission, are progressively entering the field of molecular probes with a handful of molecular/supramolecular discrete complexes. Here we show that nonanuclear lanthanide complexes respresent a new class of solution state UC materials, and are straightforwardly crystalized from $\mathrm{LnCl}_{3} .6 \mathrm{H}_{2} \mathrm{O}$ salts, triethylamine and acetylacetone, retaining their structural integrity in solution. For a composition of one Tb per eight $\mathrm{Yb}$ the nonanuclear clusters display a very efficient upconversion phenomenon with $\mathrm{Tb}$ luminescence in the visible region upon $980 \mathrm{~nm}$ NIR excitation of $\mathrm{Yb}$. An unprecedented value of $1.0 \times 10^{-7}$ was obtained for the UC efficiency at only $2.86 \mathrm{~W} / \mathrm{cm}^{2}$, demonstrating these new molecular clusters to be up to 26 times more efficient than the best current molecular systems, the UC being observed down to a concentration of $10 \mathrm{nM}$.

\section{Introduction}

While UC has been observed and studied for more than sixty years, ${ }^{1}$ it is only in the last decade that researchers are playing with the coordination chemistry toolkit in an attempt to observe it at the molecular scale in solution. ${ }^{2}$ The main difficulty of the molecular approach relies in the presence of organic matter constituting the ligands and the solvent molecules. The multistep mechanisms of UC require that the NIR intermediate excited state persists sufficiently long enough to enable the further climbing of the energy ladder. As the main source of non-radiative deactivation of excited states is attributed to energy transfer to the overtones of vibrational bands in the $\mathrm{NIR},{ }^{3}$ decreasing this quenching is of paramount importance in molecular UC systems. However, by combining a judicious choice of energy donors and acceptors, a few discrete coordination complexes have been revealed as UC molecular systems in the solid state, ${ }^{4}$ but also in diluted solutions. ${ }^{2,5-7}$ In 1994, Auzel proposed the formation of "ion clusters" as being responsible for solid state cooperative UC processes observed in some doped glasses. ${ }^{8}$ Such clusters results from ion pairing at very short distances (less than $5 \AA$ ) and were later confirmed to be the origin of green cooperative UC luminescence of $\mathrm{Tb}$ observed in some doped $\mathrm{Yb} / \mathrm{Tb}$ solids. ${ }^{9}$ We thus hypothesized that chemical engineering of such clusters might lead to the observation of the cooperative photosensitization process in discrete molecular entities in solution.
Among known lanthanide (Ln) clusters, ${ }^{10}$ a family based on $\beta$ diketonate ligands attracted our attention as a result of their straightforward synthesis, ${ }^{11}$ versatility in nuclearity ${ }^{12}$ and composition, ${ }^{13}$ and small inter-Ln distances. ${ }^{14}$ The simple case of acetylacetonate ligands forming nonanuclear clusters ${ }^{12}$ particularly retained our interest with the close proximity of up to nine $\mathrm{Ln}$ atoms in a very small volume and intermetallic distances shorter than $5 \AA$. Noteworthy, a controlled doping of such clusters might allow the formation of clusters containing up to eight sensitizing ions for one emitting UC center, a situation considered to be optimum for maximizing energy transfer UC. ${ }^{15}$ Taking advantage of these prior works, we show that the cluster structures obtained in the solid state retain their integrity in solution and that the chemical composition can be tuned to obtain mixed $\mathrm{Yb} / \mathrm{Tb}$ nonanuclear complexes exhibiting outstanding UC properties in solution.

\section{Results and Discussion}

\section{Synthesis and Structural Properties}

The nonanuclear clusters of general composition $\left[\mathrm{Ln}_{9} \mathrm{~L}_{16}(\mathrm{OH})_{10}\right](\mathrm{OH})(\mathrm{L}=$ Acac = acetylacetonate, yttrium $(\mathrm{Y})$ will be integrated in the abbreviation of Ln for brevity) were obtained by adaptation of the literature procedures (Figure 1a). ${ }^{11}$ Full synthetic details and characterization of the 

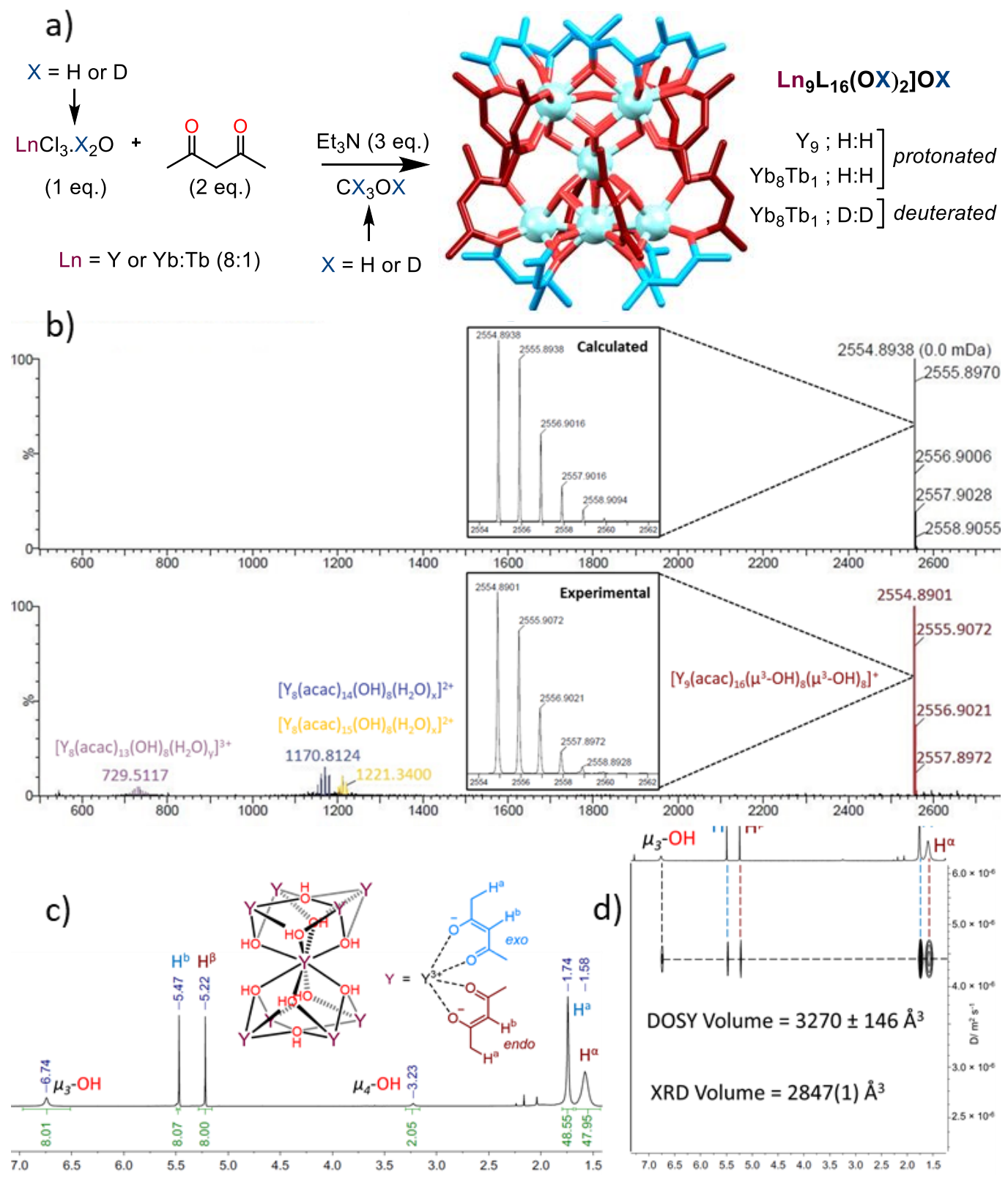

Scheme 1. a) Synthetic protocol for the preparation of the nonanuclear clusters. b) ES/MS spectra of the $Y$ nonanuclear cluster showing a major peak at 2554.8901 and the expansion of this peak with the calculated isotopic distribution. c) ${ }^{1} \mathrm{H}-\mathrm{NMR}$ and d) $2 \mathrm{D}-\mathrm{DOSY}$ spectra of the $\left[\mathrm{Y}_{9} \mathrm{~L}_{16}(\mathrm{OH})_{10}\right](\mathrm{OH})$ complex. $\left(\mathrm{CDCl}_{3}, 600 \mathrm{MHz}, 298 \mathrm{~K}\right.$

complexes can be found in the supplementary information. The solid state structure of the $\mathrm{Ln}_{9}$ complexes $^{12}$ can be viewed as two pentanuclear square pyramids sharing the apical Ln atom, with a torsion angle of approximately $45^{\circ}$ between the two pyramids, resulting in square anti-prismatic geometry at the central Ln (Figure 1a). The eight triangular faces of the pyramids are capped by $\mu_{3}-\mathrm{OH}$ groups linked to the three $\mathrm{Ln}$ at the edges of the triangles, while the four $\mathrm{Ln}$ atoms of the two square faces are connected by $\mu_{4}-\mathrm{OH}$ bonds. All Ln atoms except the central one are linked to two acetylacetonate ligands.

For the study in solution, the $\mathrm{Y}_{9}$ complex was taken as a reference due to a) the chemical similarity of $Y($ III) with $\operatorname{Ln}($ III) cations of the end of the Ln series (ionic radii of 1.027, 1.019 and $1.015 \AA$ respectively for $\mathrm{Dy}(\mathrm{III}), \mathrm{Y}(\mathrm{III})$ and $\mathrm{Ho}(\mathrm{III})$ for a coordination number of 8$)^{16}$ and b) its diamagnetic nature allowing for an easy interpretation of NMR experiments. The complex was redissolved in $\mathrm{CH}_{3} \mathrm{OH}$ and first studied by electrospray mass spectrometry (Figure $1 \mathrm{~b}$ and S1, S2). The spectrum displays one major peak at $2554.89 \mathrm{~m} / \mathrm{z}$ units corresponding to the monocharged $\left[\mathrm{Y}_{9} \mathrm{~L}_{16}(\mathrm{OH})_{10}\right]^{+}$complex and minor peaks were observed attributed to doubly charged polyhydrated clusters having lost one $\mathrm{YL}_{1}$ unit or one $\mathrm{YL}_{2}$ unit (Figure S1) and triply charged polyhydrated clusters missing one $\mathrm{YL}_{3}^{-}$unit (Figure S2)

The ${ }^{1} \mathrm{H}$-NMR spectrum of the $\mathrm{Y}$ cluster in $\mathrm{CDCl}_{3}$ (Figure $1 \mathrm{c}$ ) presents time-averaged $C_{4}$ symmetry, with two sets of methyl groups (48H each) and two sets of $\mathrm{CH}(8 \mathrm{H}$ each) for the Acac ligands, and two broad singlets integrating for $8 \mathrm{H}$ and $2 \mathrm{H}$ 
corresponding to the two sets of $\mathrm{OH}$ bonds observed in the solid state structure (vide supra). ${ }^{12}$ The different NMR experiments $\left({ }^{13} \mathrm{C}, \mathrm{HSQC}, \mathrm{HMQC}, \mathrm{ROESY}\right.$ and DOSY Figure S3-7) pointed to the two sets of Acac ligands originating from two families of independent ligands, which were ascribed to eight Acac ligands capping the top and the bottom of the cluster (exo ligands, blue in Figure 1a and $\mathrm{c}$ ) and eight Acac ligands positioned the equatorial plane of the cluster (endo ligands, red in Figure 1a and c). Each of these ligands can easily rotate to exchange the positions of the two methyl groups, but the exchange between the exo and endo positions is slow on the NMR time scale at 298 K. The 2D-DOSY NMR spectrum was particularly informative (Figure $1 \mathrm{~d}$ and Figure $\mathrm{S7}$ ), as the average value of the diffusion coefficients at $4.37 \times 10^{-10} \mathrm{~m}^{2} . \mathrm{s}^{-1}$ represents a volume of $3270 \pm$ $150 \AA^{3}$, in good agreement with the crystal structure of the complex in the solid state $\left(2847(1) \AA^{3}\right) .{ }^{12}$

Considering that the maximization of the number of sensitizing ions per emitting centers (activators) is expected to optimize the UC process, ${ }^{15}$ we then prepared mixed clusters containing 8 $\mathrm{Yb}$ donors and one $\mathrm{Tb}$ acceptor by simply starting from a 1:8 $\mathrm{Tb}: \mathrm{Yb}$ mixture. The complexes were obtained from $\mathrm{CH}_{3} \mathrm{OH}$ and $\mathrm{LnCl}_{3} .6 \mathrm{H}_{2} \mathrm{O}$, or from $\mathrm{CD}_{3} \mathrm{OD}$ and $\mathrm{LnCl}_{3} \cdot 6 \mathrm{D}_{2} \mathrm{O}$ starting salts, respectively referred to $\mathrm{H}: \mathrm{H}$ or $\mathrm{D}: \mathrm{D}$. The solid-state infrared (IR) spectra of the novel clusters display a net shift of the $\mu_{x}-\mathrm{OH}(\mathrm{D})$ vibrational band from $3316 \mathrm{~cm}^{-1}$ to $2439 \mathrm{~cm}^{-1}$ upon deuteration (Figure S8 for the D;D IR spectrum). Powder XRD of the $\mathrm{H}: \mathrm{H}$ complex (Figure S9) clearly demonstrated that, in the solid state, the synthesized $\left[\mathrm{Yb}_{8} \mathrm{~Tb}_{1}\right]$ cluster are isostructural to the reported $\left[\mathrm{Tb}_{9}\right]$ ones. ${ }^{12}$ TEM-EDX analysis were performed on 10 different points of monocrystals of $\mathrm{H}: \mathrm{H}$, giving a composition of $89.6 \pm 2.4 \%$ of $\mathrm{Yb}$ and $10.4 \pm 2.4 \%$ of $\mathrm{Tb}$, in good agreement with the $89.1 \%$ of $\mathrm{Yb}$ and $10.9 \%$ of $\mathrm{Tb}$, introduced in the synthesis. Alternatively, the $\mathrm{Yb}$ and $\mathrm{Tb}$ contents of the heteronuclear clusters were determined by ICP-AES measurements confirming the $\mathrm{Yb}_{8} \mathrm{~Tb}_{1}$ composition with an estimated error of \pm 0.1 atomic unit.

\section{Spectroscopic and Upconversion Investigations}

The UV-Vis-NIR absorption spectrum of the $\mathrm{H}: \mathrm{H}$ complex in $\mathrm{CH}_{3} \mathrm{OH}$ is presented in Figure 2 (Figure $\mathrm{S} 10$ for the D:D complex). It is composed of a broad absorption band in the UV region at $291 \mathrm{~nm}\left(\varepsilon=14.8 \times 10^{4} \mathrm{M}^{-1} \cdot \mathrm{cm}^{-1}\right)$, attributed to transitions centered on the Acac ligands. ${ }^{17}$ In the NIR, the spectrum

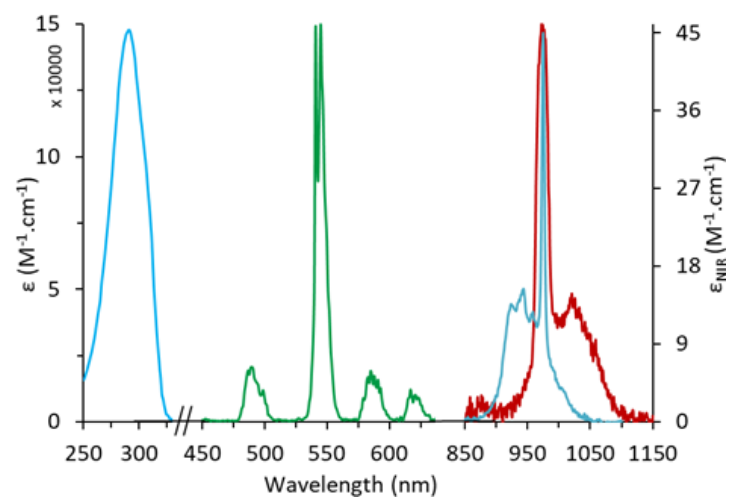

Figure 2. a) UV-Vis-NIR absorption spectrum (blue) b) normalized emission spectra $\left(\lambda_{\text {exc }}=292 \mathrm{~nm}\right)$ in the visible (green) and NIR (red) domains for the $\mathrm{H}: \mathrm{H}\left[\mathrm{Yb}_{8} \mathrm{TbL}_{16}(\mathrm{OH})_{10}\right](\mathrm{OH})$ cluster in $\mathrm{CH}_{3} \mathrm{OH}$.

displays a broad absorption band at $975 \mathrm{~nm}\left(\varepsilon=46.9 \mathrm{M}^{-1} \cdot \mathrm{cm}^{-1}\right.$ in $\mathrm{CH}_{3} \mathrm{OH} ; \varepsilon=51.7 \mathrm{M}^{-1} \cdot \mathrm{cm}^{-1}$ in $\mathrm{CD}_{3} \mathrm{OD}$ ) attributed to the ${ }^{2} \mathrm{~F}_{7 / 2} \rightarrow$ ${ }^{2} \mathrm{~F}_{5 / 2}$ transition of $\mathrm{Yb}$. At high concentrations, a very weak absorption band can be observed around $485 \mathrm{~nm}\left(\varepsilon=0.055 \mathrm{M}^{-}\right.$ ${ }^{1} . \mathrm{cm}^{-1}$, Figure S10) attributed to the ${ }^{7} \mathrm{~F}_{6} \rightarrow{ }^{5} \mathrm{D}_{4}$ transition of Tb. Upon excitation into the Acac absorption band (292 nm), the complexes display two sets of emission bands (Figure 2 ), those in the visible region corresponding to the ${ }^{5} D_{4} \rightarrow{ }^{7} \mathrm{~F}_{J}(J=6$ to 3$)$ transitions of $\mathrm{Tb}^{18}\left(\Phi_{T b}=1.5 \%\right.$ in $\left.\mathrm{CH}_{3} \mathrm{OH}\right)$, and a broad emission band peaking at $975 \mathrm{~nm}$ corresponding to the ${ }^{2} \mathrm{~F}_{5 / 2} \rightarrow{ }^{2} \mathrm{~F}_{7 / 2}$ transition of $\mathrm{Yb}\left(\Phi_{Y b}=0.08 \%\right)$. The corresponding luminescence lifetimes were $0.95 \mathrm{~ms}$ for $\mathrm{Tb}$ and $<1 \mu \mathrm{s}$ for $\mathrm{Yb}$ in $\mathrm{CH}_{3} \mathrm{OH}$. For the $\mathrm{D}$ :D complex in $\mathrm{CD}_{3} \mathrm{OD}$, the lifetimes increase to $16.6 \mu \mathrm{s}$ for $\mathrm{Yb}$ and $1.12 \mathrm{~ms}(95 \%)$ and $350 \mu \mathrm{s}(5 \%)$ for $\mathrm{Tb}$, indicating two different chemical environments. From previous site specific doping experiments, ${ }^{11}$ the larger $\mathrm{Tb}$ ion is expected to be predominantly positioned at the central site of the cluster and one might relate this to the longer lifetime value regarding the relative intensities of the two components. However, the excitation through the ligand absorption bands is expected to favor the emission from the cations positioned at the periphery of the cluster to which Acac ligands are directly bonded and the attribution of the lifetimes to the two different sites is still subject to doubts.

From the NIR absorption band of $\mathrm{Yb}$ and weighting the absorption coefficients by the number of $\mathrm{Yb}$ atoms (8), it was possible to calculate the radiative lifetime of $Y b, \tau_{\text {rad }}$, according
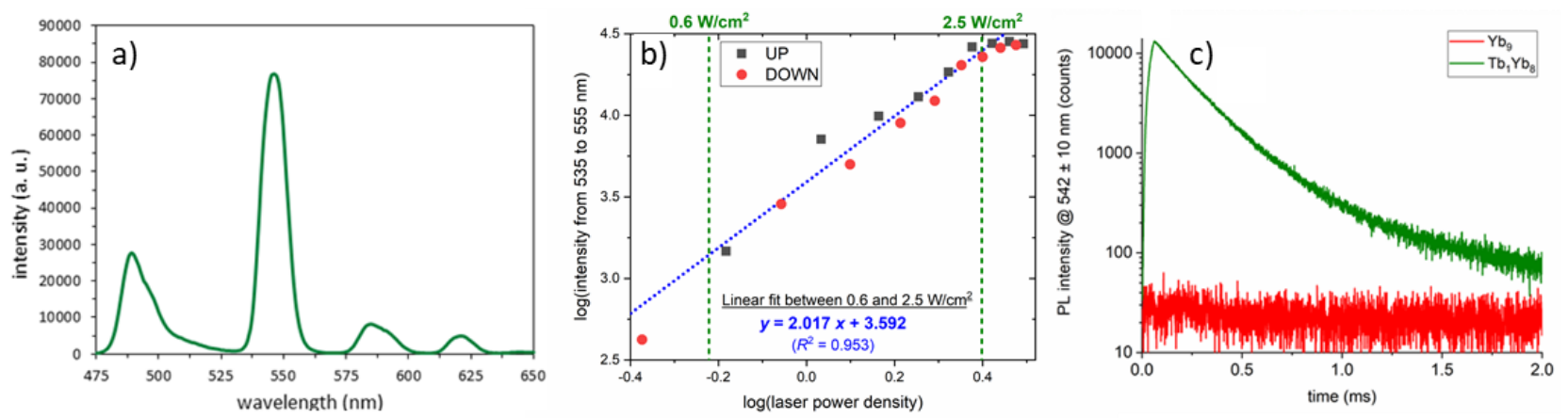

Figure 3. a) UC emission spectrum of the (D:D) complex in $\mathrm{CD}_{3} \mathrm{OD}\left(c=2.0 \mathrm{mM}, P=2.86 \mathrm{~W} . \mathrm{cm}^{-2}\right.$, 国 exc $\left.=980 \mathrm{~nm}\right)$. b) UC intensity as a function of the incident pump power density in a $\mathrm{Log} / \mathrm{Log}$ scale (squares correspond to increasing pump intensities and red dots for decreasing ones). Blue dotted 
line represents the linear regression of the data. c) Temporal evolution of the UC emission at $542 \mathrm{~nm}$ upon $60 \mu \mathrm{s}$ pulsed excitation at $980 \mathrm{~nm}$ for clusters of $\mathrm{Yb}_{8} \mathrm{~Tb}_{1}$ (green) and $\mathrm{Yb}_{9}$ (red) compositions

to the methodology described by Werts and coworkers. ${ }^{19}$ Full experimental description of the method is given in the supplementary information (Section S3). Values of $\tau_{\text {rad }}$ between 578 and $683 \mu$ s were obtained (Table S1) for the H:H and D:D complexes in $\mathrm{CH}_{3} \mathrm{OH}$ or $\mathrm{CD}_{3} \mathrm{OD}$, affording a mean value of $639 \pm$ $28 \mu \mathrm{s}$. The $\mathrm{Yb}$ lifetimes being too short to be measured with our setup in $\mathrm{CH}_{3} \mathrm{OH}$, only values in $\mathrm{CD}_{3} \mathrm{OD}$ for the $\mathrm{D}: \mathrm{D}$ complex were used (Table $\mathrm{S} 1$ ) to calculate a $\mathrm{Yb}$ centered luminescence quantum yield of $2.6 \%$ with a modest sensitization efficiency of $22 \%$ by excitation through the Acac ligands.

The most striking feature of the mixed cluster was observed when the $D: D$ complex in $C_{3} O D$ was excited in the NIR absorption band of $\mathrm{Yb}$ at $980 \mathrm{~nm}$ (Figure 3a), resulting in a strong emission in the visible region with the typical spectral signature of the Tb emission.

The luminescence intensity was recorded as a function of the incident pump power density and the logarithmic representation (Figure $3 b$ ) presents a quasi linear profile with a slope of two, accrediting the two photon UC process. ${ }^{20,21}$

Analysis of the temporal evolution of the UC intensity at $542 \mathrm{~nm}$ upon pulsed excitation (Figure $3 c$ ) evidences a first slow rise during the $60 \mu$ s pumping period, indicative of a cooperative photosensitization mechanism, ${ }^{7,21}$ followed by a bi-exponential decay $\left(\tau_{1}=170 \mu \mathrm{s}(93 \%) ; \tau_{2}=390 \mu \mathrm{s}(7 \%)\right)$. The same experiment performed on the $\mathrm{Yb}_{9}$ cluster resulted in the absence of the green emission, confirming that the emission arises from the Tb atoms.

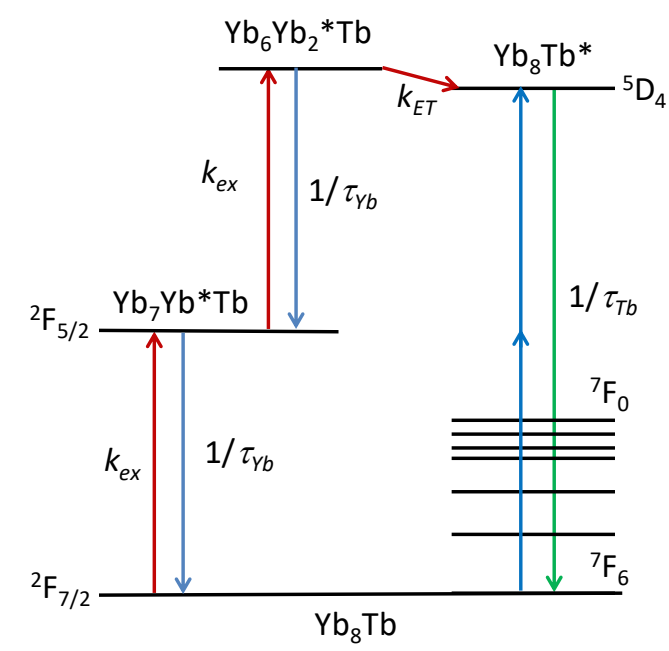

] $]$ uc does not take into account the factor 2 sometimes used to account for the two-photon process. ${ }^{5}$ This value is 92 to 377 times larger than that of the best UC Er complexes $\left(1.95 \times 10^{-9}<\right.$ ? $\left.u c<8 \times 10^{-9} @ 21 \mathrm{~W} . \mathrm{cm}^{-2}\right),{ }^{5}$ and 26 times larger than previous

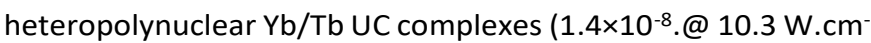
$\left.{ }^{2}\right)^{6}$ The importance of reducing excited-state deactivation by $\mathrm{OH}$ oscillators is exemplified by the 18-fold larger ?uc for the D:D cluster compared to its $\mathrm{H}: \mathrm{H}$ congener (Table $\mathrm{S} 1$ ).

Finally, the sensitivity of the UC emission was investigated by decreasing the concentration of the solution down to the lowest observable emission. At micromolar concentrations, the Tb UC emission signal was still fully resolvable and the lower limit of detection with our setup at full power $\left(P=10.3 \mathrm{~W} / \mathrm{cm}^{2}\right)$ was determined to be $10 \mathrm{nM}$ (Figure S11).

\section{Conclusions}

The doping of $\mathrm{Yb}$ nonanuclear clusters by $\mathrm{Tb}$ emitting ions afforded heteronuclear $\left[\mathrm{Yb}_{8} \mathrm{~Tb}(\mathrm{Acac})_{16}(\mathrm{OH})_{10}\right](\mathrm{OH})$ clusters. In solution, these clusters display a cooperative UC photosensitization process which was demonstrated to be more than one order of magnitude more efficient than previous molecular or supramolecular UC probes, ${ }^{2,5-7}$ being observable at concentration as low as $10 \mathrm{nM}$. Noteworthy, the tremendous potential of other readily accessible 6 -diketonate ligands, coupled with the wide variety of Ln donor-acceptor dyads and the structural diversity of such clusters, opens avenues to even more efficient UC systems.

\section{Conflicts of interest}

There are no conflicts to declare.

\section{Acknowledgements}

Financial support is gratefully acknowledged from the French Ministère de l'Education Nationale et de la Recherche and the French Canada research Fund and the LabEx CSC (ANR-10-LABX0026-CSC). Dr Jean-Marc Strub and Dr. Bruno Vincent are acknowledged for performing ESI-MS and DOSY NMR experiments, respectively.

Figure 4. Proposed cooperative photosensitization process UC mechanism.

The proposed mechanism (Figure 4) entails a first absorption of a photon by an $\mathrm{Yb}$ atom of the $\left[\mathrm{Yb}_{8} \mathrm{~Tb}_{1}\right]$ cluster, leading to a $\left[\mathrm{Yb}_{7} \mathrm{Yb} * \mathrm{~Tb}\right]$ species, followed by the absorption of a photon by a second $\mathrm{Yb}$, engendering the $\left[\mathrm{Yb}_{6} \mathrm{Yb}^{*}{ }_{2} \mathrm{~Tb}_{1}\right]$ intermediate. Cooperative energy transfer to $\mathrm{Tb}$ at a rate $k_{E T}$ forms the $\left[\mathrm{Yb}_{8} \mathrm{~Tb}_{1}{ }^{*}\right] \mathrm{Tb}$ centered excited states which decay to the ground state by emission of visible light.

The UC quantum yield (?uc), calculated following published procedures, 22,23 was determined to be $1 \times 10^{-7}$ (@ 2.86 W.cm ${ }^{-2}$ ). As ?uc is directly proportional to the power of the excitation source for a two-photon process, ${ }^{22}$ and the calculation of the

\section{Notes and references}

1 a) P. A. Franken, A. E. Hill, C. W. Peters, G. Weinreich, Phys. Rev. Lett. 1961, 7, 118-120; b) W. Kaiser, C. G. B. Garret, Phys. Rev. Lett. 1961, 7, 229-231; c) F. Auzel, Chem. Rev. 2004, 104, 139-173.

2 a) L. Aboshyan-Sorgho, C. Besnard, P. Pattison, K. R. Kittilstved, A. Aebischer, J.-C. G. Bünzli, A. Hauser, C. Piguet, Angew. Chem., Int. Ed. 2011, 50, 4108-4112; Angew. Chem., 2011, 123, 4194-4198; b) A. Nonat, C. F. Chan, T. Liu, C. PlatasIglesias, K.-L. Wong, L. J. Charbonnière, Nat. Commun. 2016, 7, 11978. 
3 a) C. Doffek, N. Alzakhem, C. Bischof, J. Wahsner, T. GüdenSilber, J. Lügger, C. Platas-Iglesias, M. Seitz, J. Am. Chem. Soc. 2012, 134, 16413-16423; b) A. Beeby, I. M. Clarkson, R. S. Dickins, S. Faulkner, D. Parker, L. Royle, A. S. de Sousa, J. A. G. Williams, M.Woods,J. Chem. Soc., Perkin Trans. 2 1999, 3, 493-504.

4 a) J. Kalmbach, C. Wang, Y. You, C. Förster, H. Schubert, K. Heinze, U. Resch-Genger, M. Seitz, Angew. Chem. Int. Ed. 2020 https://doi-org/10.1002/anie.202007200; b) J. T. Mo, Z. Wang, P.Y. Fu, L.Y. Zhang, Y.N. Fan, M. Pan, C.Y. Su, CCS Chem. 2020, 2, 729-738.

5 B. Golesorkhi, A. Fürstenberg, H. Nozary, C. Piguet, Chem. Sci. 2019, 10, 6876-6885.

6 N. Souri, P. Tian, C. Platas-Iglesias, K.-L. Wong, A. Nonat, L. J. Charbonnière, J. Am. Chem. Soc. 2017, 139, 1456-1459.

7 A. Nonat, S. Bahamyirou, A. Lecointre, F. Przybilla, Y. Mély, C. Platas-Iglesias, F. Camerel, O. Jeannin, L. J. Charbonnière, J. Am. Chem. Soc. 2019, 141, 1568-1576.

8 F. Auzel, D. Meichenin, F. Pellé, P. Goldner, Opt. Mater. 1994, 4, 35-41.

9 a) G.M. Salley, R. Valiente, H.U. Güdel, Phys. Rev. B, 2003, 67 134111. b) G.M. Salley, R. Valiente, H.U. Güdel, J. Lumin. 2001, 94-95, 305-309.

10 J. Kobylarczyk, E. Kuzniak, M. Liberka, S. Chorazy, B. Sieklucka, R. Podgajny, Coord. Chem. Rev. 2020, 419, 213394.

11 F. Baril-Robert, S. Petit, G. Pilet, G. Chastanet, C. Reber, D. Luneau, Inorg. Chem. 2010, 49, 10970-10976.

12 S. Petit; F. Baril-Robert,; G. Pilet,; C. Reber,; D. Luneau, Dalton Trans., 2009, 6809-6815.

13 D. Guettas, C. M. Balogh, C. Sonneville, Y. Malicet, F. Lepoivre, E. Onal, A. Fateeva, C. Reber, D. Luneau, O. Maury, G. Pilet, Eur. J. Inorg. Chem. 2016, 3932-3938.

14 G. Xu, Z.-M. Wang, Z. He, Z. Lu, C.-S. Liao, C.-H. Yan, Inorg. Chem. 2002, 41, 6802-6807.

15 D. Zare, Y. Suffrejn, L. Guénée, S.V. Eliseeva, H. Nozary, L. Aboshyan-Sorgho, S. Petoud, A. Hauser, C. Piguet, Dalton Trans. 2015, 44, 2529-2540.

16 R.D. Shannon, Acta Cryst. 1976, A32, 751-767.

17 G. Napier, J. D. Neilson, T.M. Sheperd, Chem. Phys. Lett. 1975, 31, 328-330.

18 J.-C. G. Bünzli, Chem. Rev. 2010, 110, 2729-2755.

19 M.H. V. Werts, R. T. F. Jukes, J. W. Verhoeven, Phys. Chem. Chem. Phys., 2002, 4, 1542-1548.

20 M. Pollnau, D. R. Gamelin, S. R. Lüthi, H. U. Güdel, M. P. Hehlen, Phys. Rev. B, 2000, 61, 3337-3346.

21 G. M. Salley, R. Valiente, H. U. Güdel, J. Phys.: Condens. Matter 2002, 14, 5461.

22 G. Chen, H. Qiu, P. N. Prasad, X. Chen, Chem. Rev. 2014, 114, 5161-5214.

23 N. Weibel, L. J. Charbonnière, M. Guardigli, A. Roda, R. Ziessel, J. Am. Chem. Soc. 2004, 126, 4888-4896. 